\title{
Numerical Analysis of Slot Position of Rectangular U Slot Microstrip Patch Antenna
}

\author{
Harleen Kaur ${ }^{1}$, Balwinder Singh Dhaliwal ${ }^{2}$ \\ ${ }^{I}$ Sant Baba Bhag Singh Institute of Engineering and Technology, JALANDHAR, India. \\ ${ }^{2}$ Guru Nanak Dev Engineering College, LUDHIANA, India.
}

\begin{abstract}
The main focus of this paper is to study and analyze how the performance of rectangular $U$ slot antenna is affected by the variation of $U$ slot position. The work presented herein is a simulation based study. Experimentally, it has been revealed that variations in parameters such as the width and length of the U-slot, height and size of the patch, probe size and location as well as substrate permittivity can dramatically change the antenna's behavior. Till date, no analytical methods have been developed that accurately relate the complex relationships between the antenna dimensions and individuality. This paper describes the behavior of antenna with change of $U$ slot position. A numerical solution is obtained by varying the various positions of $U$ slot along all the axis and the effect of $U$ slot position on various antenna output parameters is analyzed.
\end{abstract}

Index Terms: Microstrip Patch Antenna, Return Loss, Gain, Bandwidth.

(C) 2016 Published by MECS Publisher. Selection and/or peer review under responsibility of the Research Association of Modern Education and Computer Science

\section{Introduction}

With the increased necessities for personal and mobile communications, the demand for smaller and lowprofile antennas has brought the Microstrip Antennas (MSA) to the forefront. Since, MSA are known to possess properties like low size, weight, cost, performance, ease of installations, these antennas provide a very good performance [1]. MSA are also known as patch antenna due to the radiating patch on one side of the dielectric substrate and ground on other side. The physical characteristics of MSA are compatible for use in mobile phones, Bluetooth personal networks and wireless local networks [2]

Even though these antennas have lots of advantages but it also suffers from few shortcomings like small efficiency, low power, very narrow frequency bandwidth [3]. The basic and most commonly used MSA is rectangular MSA. The MSA suffer from the major disadvantage of narrow bandwidth [4]. A number of

\footnotetext{
* Corresponding author.

E-mail address: harleen.chawla86@gmail.com,bs_dhaliwal@gndec.ac.in
} 
methods have been worked out by the researchers to overcome the limitations of MSA. The limitations of MSA can be prevailed over by increasing the permittivity of the substrate or by increasing the height of the patch. However, the results of both of these methods are inadequate since increasing patch height results in modifying the low-profile feature of the patch whereas the implementation of second is subject to material availability and suitability [5]. Another technique includes the use of the parasitic elements lying on same layer or another layer (stacked). The aperture coupled excitations also used to achieve the wider bandwidth but this method is having a complication of fabrication process [6].

The various slot shapes are available to fulfill the requirement of improvement in bandwidth. The etching of U slot on the Microstrip patch is considered to be a simple design [7] .Such a design does not make use of stacked or coplanar parasitic patches because either of these increases the thickness or the lateral size of the antenna. So, while changing the current distribution on the Microstrip patch enhancing the impedance bandwidth with sometimes more than one resonant frequency are obtained [8]. The loading of slot on the radiating patch results in increase of the current length that results in lowering fundamental resonance frequency which corresponds to reduced antenna size when compared to conventional patch antenna for a given resonant frequency.

\section{Related Work}

The earlier analysis and the empirical technique of $U$ slot antenna are based on dimensional invariance relationships observed in the U-slot geometry and empirical design equations [9]. The strength of this method is that it converges on the optimized design quickly - if the desired frequency lies in the range in which the design equations are reliable. The constraint of former method is that the design equations were developed for specific values of substrate permittivity and thickness. The impracticality of deriving similar equations for all possible combinations of permittivity and thickness limits the usefulness of this technique. Also rather than chamfering any corner of the probe feed square patch microstrip antenna the symmetrical U-slot can be employed to produce the two orthogonal modes for circular polarization. The parametric study has also been carried out to analyze the effects caused by different arm lengths of the U-slot. Both experimental and theoretical results of the antenna had been verified [10]. The physical parameters for example length of U slot, width of $U$ slot, height and size of patch, probe location, substrate permittivity can greatly affect the antenna's performance[6]. In this paper the effect of various values of slot length and slot width on return loss and gain has been analyzed. After this the numerical solution is obtained for these values. The characteristics of the classical stacked and U-slot patch antenna were also examined.

\section{Variation of Positions of U Slot of the Patch}

In this paper, the effect of variation of $U$ slot position on rectangular $U$ slot antenna's (shown in Fig 3.1) performance is analyzed. The position of $U$ slot is varied w.r.t. centre of the slot. A numerical solution of the antenna is obtained for various values of the $U$ slot position and the effect of these parameters on the return loss, gain, bandwidth, frequency of the antenna are studied.

The antenna geometry provided in [9] served as a basis for the analysis of $U$ slot rectangular antenna which was carried out using a method of moments simulation package. The initial geometric and material properties are provided in table 1 .

Several parameters are found to have significant effects on antenna's behaviour e.g. substrate thickness, slot width etc. Here the position of $U$ slot is varied to evaluate the effect on antenna's behaviour. The slot position is varied such that the slot arms do not come out of the patch. 

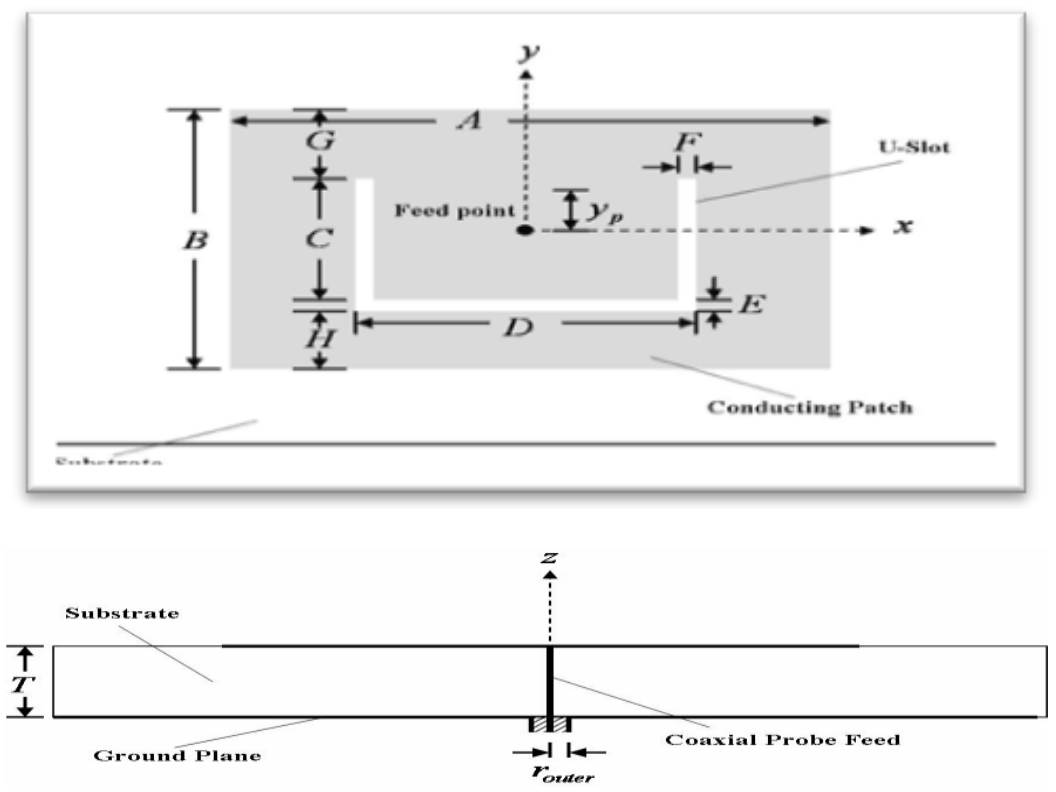

Fig.3.1. Geometry of the Rectangular U-Slot Microstrip Patch Antenna [9]

Table 1. Dimensions and Material Properties of the Initial U-Slot Antenna used in the Parametric Studies

\begin{tabular}{|lcccccccccc|}
\hline $\mathbf{A}$ & $\mathbf{B}$ & $\mathbf{C}$ & $\mathbf{D}$ & $\mathbf{E}$ & $\mathbf{F}$ & $\mathbf{H}$ & $\mathbf{R}$ & $\mathbf{T}$ & $\begin{array}{c}\text { Offset } \\
\mathbf{m m}\end{array}$ & $\begin{array}{c}\boldsymbol{E}_{\mathbf{r}} \\
\mathbf{m m}\end{array}$ \\
$\mathbf{m m}$ & $\mathbf{m m}$ & $\mathbf{m m}$ & $\mathbf{m m}$ & $\mathbf{m m}$ & $\mathbf{m m}$ & $\mathbf{m m}$ & $\mathbf{m m}$ & $\mathbf{m m}$ & $\mathbf{0}$ & $\mathbf{0}$ \\
\hline 36 & $\mathbf{2 6}$ & $\mathbf{1 2}$ & $\mathbf{6}$ & $\mathbf{2}$ & $\mathbf{2}$ & $\mathbf{4}$ & $\mathbf{0 . 5}$ & $\mathbf{5 . 0}$ & $\mathbf{0}$ & $\mathbf{2}$ \\
\hline
\end{tabular}

\subsection{U Slot Position Variation along Positive Y Axis}

This involves the variation of the position of the $\mathrm{U}$ slot along positive $\mathrm{Y}$-axis. The variation is brought in the co-ordinates of the centre of the slot. Hence we can say that the position of the centre of the slot is varied. The last possible point along positive $\mathrm{Y}$ axis is $(0,5)$. The $U$ slot centre points are taken as $(0,0),(0,1),(0,2),(0,3)$, $(0,4)$ and $(0,5)$. This variation of $U$ slot results in change of the various parameters. The parameters like gain, resonant frequency are tending to degrade in their performance. Also the other parameters are also being affected by this variation.

\subsection{U Slot Position Variation along Negative Y Axis}

Here the position of $\mathrm{U}$ slot is varied along negative $\mathrm{Y}$ axis. The last possible point along negative $\mathrm{Y}$ axis is $(0,-5)$. The $\mathrm{U}$ slot centre points are taken as $(0,-3),(0,-4),(0,-5)$. While moving from the origin towards negative axis, it is realized that the values of all parameters are changing.

\subsection{U Slot Position Variation along Positive X Axis}

This involves the variation of position of $U$ slot along positive $X$ axis. The variation of $U$ slot is taken in the form of centre of $U$ slot. The last possible point along positive $X$ axis is $(9,-2)$. The $U$ slot centre points are taken as $(1,-2),(2,-2),(3,-2),(4,-2),(5,-2),(6,-2),(7,-2),(8,-2),(9,-2)$. 


\subsection{U Slot Position Variation along Negative $X$ Axis}

Here the position of $U$ slot is varied along negative $\mathrm{X}$ axis.. The last possible point along negative $\mathrm{X}$ axis is $(-9,-2)$. The U slot centre points are taken as $(-1,-2),(-2,-2),(-3,-2),(-4,-2),(-5,-2),(-6,-2),(-7,-2),(-8,-2),(-$ $9,-2)$.

\section{Results and Discussion}

\subsection{Results of Variation of Position of U Slot w.r.t. Positive Y Axis}

The centre of $U$ slot is varied to various points along positive y axis and the antenna parameters such as frequency, return loss, gain and bandwidth are noted. The following graph shows the variation of $U$ slot position and its effect on various parameters.

Fig. 4.1 and 4.2 represents the effect of $U$ slot position on frequency and return loss of the antenna. Fig. 4.1 shows that as the centre of $U$ slot is shifted away from the origin $(0,0)$ along positive $y$-axis, the resonant frequency shifts towards the upper end of frequency. Fig. 4.2 shows the degradation in return loss with increase of positive y axis.

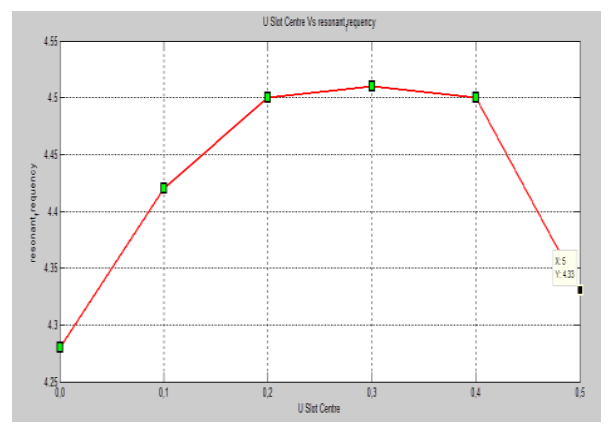

Fig.4.1. Plot of U Slot Centre and Frequency along Positive Y Axis

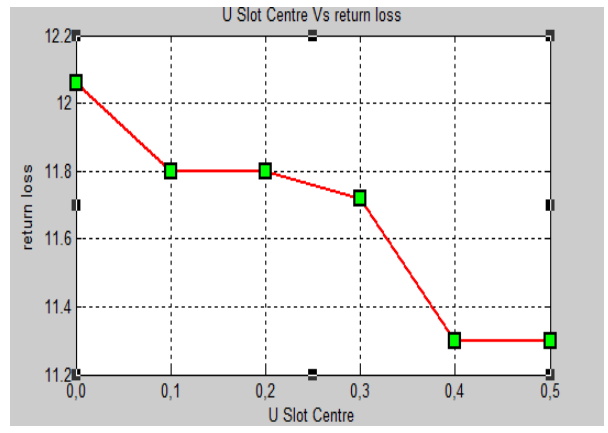

Fig.4.2. Plot of U Slot Centre and Return Loss along Positive Y Axis.

Fig. 4.3 and 4.4 represents the effect of $U$ slot position on gain and bandwidth of the antenna. Fig. 4.3 shows that as the centre of $U$ slot is shifted away from the origin $(0,0)$ along positive $Y$-axis, the value of the gain starts to decrease. Fig.4.4 shows the degradation in bandwidth with the shifting of $U$ slot centre away from the origin. 


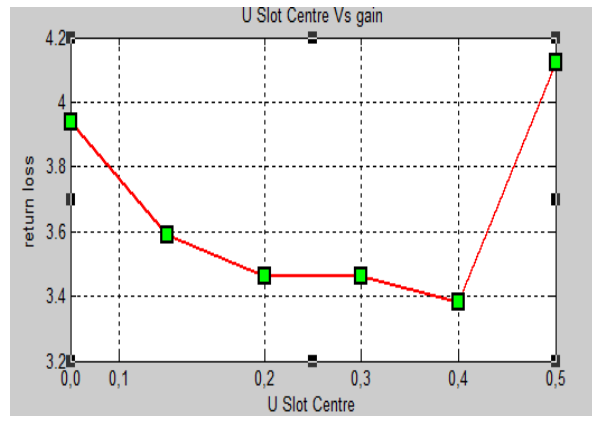

Fig.4.3. Plot of U Slot Centre and Gain along Positive Y Axis

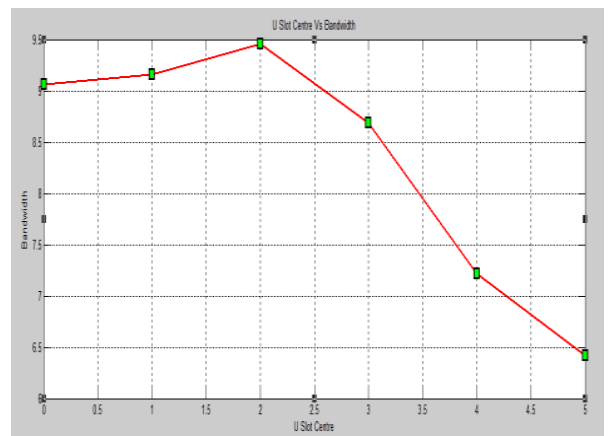

Fig.4.4. Plot of U Slot Centre and Bandwidth along Positive Y Axis

\subsection{Variation of Position of U Slot w.r.t. Negative Y Axis}

The second step is to vary the centre of $U$ slot along negative y axis and note the output parameters such as frequency, return loss, gain and bandwidth. The following graph shows the variation of $U$ slot position and its effect on various parameters.

Fig. 4.5 and 4.6 represents the effect of $U$ slot position on frequency and return loss of the antenna. Fig. 4.5 illustrates the drop of resonant frequency towards the lower end of frequency while the centre of $U$ slot is shifted away from the origin $(0,0)$ along negative $\mathrm{Y}$-axis. Fig. 4.6 yields the better results in return loss with the shifting of $U$ slot centre away from the origin along negative $y$ axis.

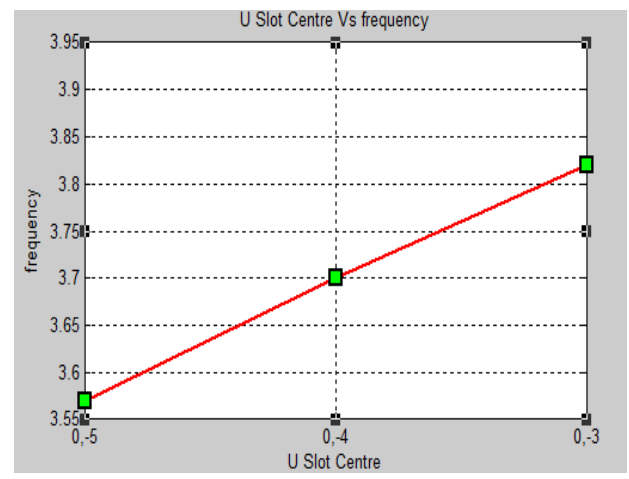

Fig.4.5. Plot of U Slot Centre and Frequency of Negative Y Axis 


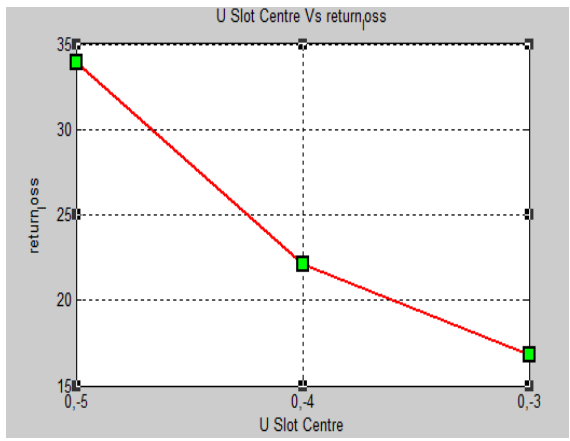

Fig.4.6. Plot of U Slot Centre and Return Loss of Negative Y Axis

Fig. 4.7 and 4.8 represents the effect of $U$ slot position on gain and bandwidth of the antenna. In Fig. 4.7 it is shown that there is an increase of gain having the shift in centre of $U$ slot away from the origin along negative Y-axis. Fig. 4.8 shows the degradation in bandwidth with shifting of $U$ slot centre away from the origin along negative y axis.

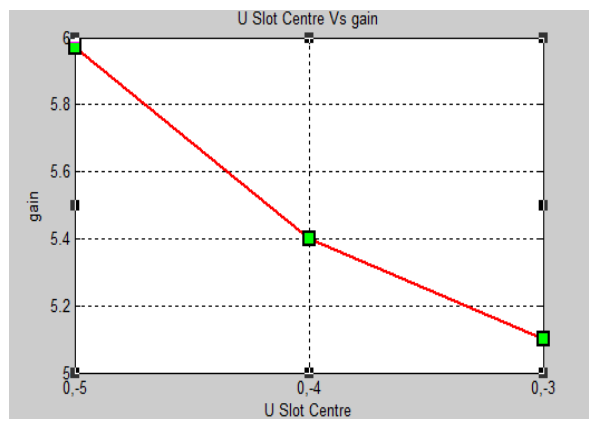

Fig.4.7. Plot of U Slot Centre and Gain of Negative Y Axis.

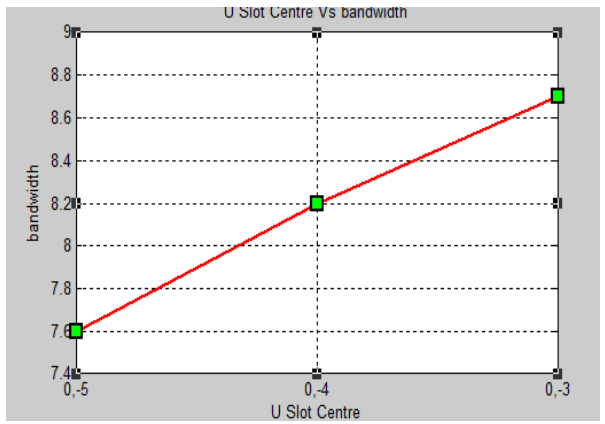

Fig.4.8. Plot of U Slot Centre and Bandwidth of Negative Y Axis

\subsection{Variation of Position of U Slot w.r.t. Positive X Axis}

The third step is to vary the centre of $\mathrm{U}$ slot along positive $\mathrm{x}$ axis and note the output parameters such as frequency, return loss, gain and bandwidth. It is observed from the variations that the variation of position of $U$ slot gives better results. But these results are up to the $U$ slot centre of $(6,-2)$. After this point, the antenna 
performance degrades abruptly.

Fig. 4.9 and 4.10 represents the effect of $U$ slot position on frequency and return loss of the antenna. Fig. 4.9 shows that as the centre of $U$ slot is shifted away from the origin along positive $\mathrm{X}$ axis, the resonant frequency shifts towards the lower end of the frequency. Fig. 4.10 shows the better results in return loss with shifting of $U$ slot centre away from the origin along negative y axis. But the better results of these parameters are up to the point $(6,-2)$.

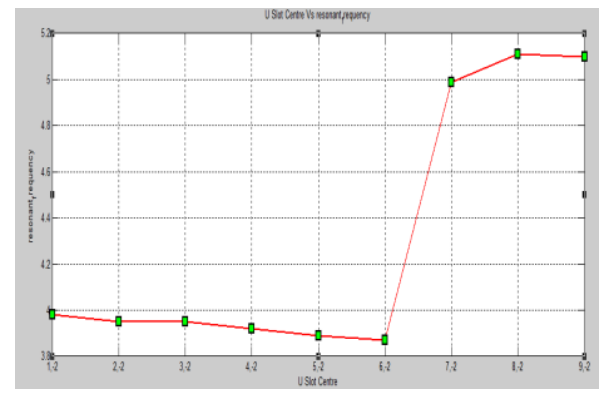

Fig.4.9. Plot of U Slot Centre and Resonant Frequency of positive X axis.

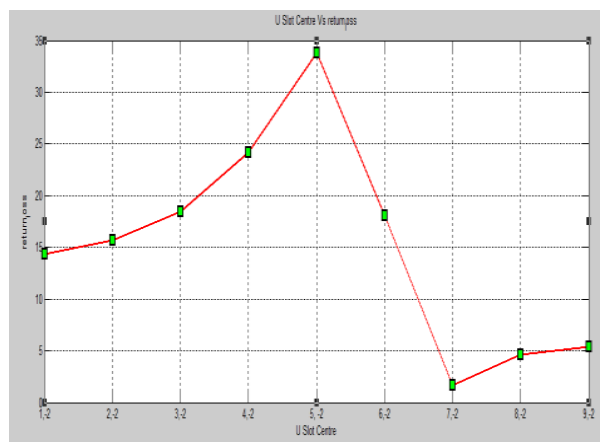

Fig.4.10. Plot of U Slot Centre and Return Loss of Positive X axis.

Fig. 4.11 and 4.12 represents the effect of $U$ slot position on gain and bandwidth of the antenna. Fig. 4.11 shows the increase in gain with shifting of $U$ slot centre away from the origin positive $\mathrm{x}$ axis. But this increase is up to the position at points of $(6,-2)$. Fig. 4.12 shows the degradation in bandwidth with shifting of $U$ slot centre along negative y axis.



Fig.4.11. Plot of U Slot Centre and Gain of Positive X Axis. 


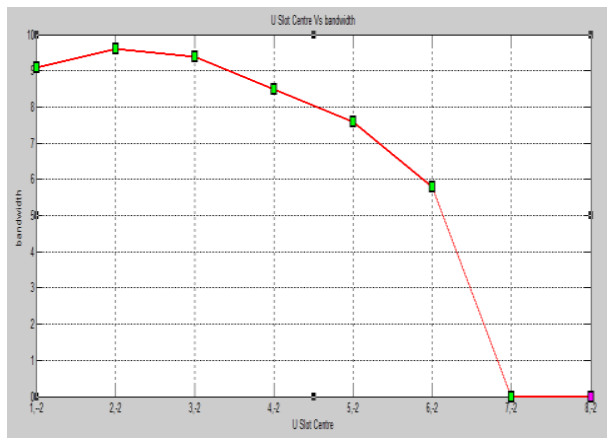

Fig.4.12. Plot of U slot Centre and Bandwidth of Positive X Axis.

\subsection{Position of $U$ Slot is varied w.r.t. Negative $X$ axis}

The next step is to vary the centre of $U$ slot along negative $X$ axis and note the output parameters such as frequency, return loss, gain and bandwidth. The following graph shows the variation of $U$ slot position and its effect on various parameters.

Fig. 4.13 and 4.14 represents the effect of $U$ slot position on frequency and return loss of the antenna. Fig. 4.13 shows that as the centre of $\mathrm{U}$ slot is shifted away from the origin along positive $\mathrm{X}$ axis, the resonant frequency shifts towards the lower end of the frequency. Fig. 4.14 shows the better results in return loss with the shifting of $U$ slot centre away from the origin along negative y axis. But the better results of these parameters are up to the point $(6,-2)$.

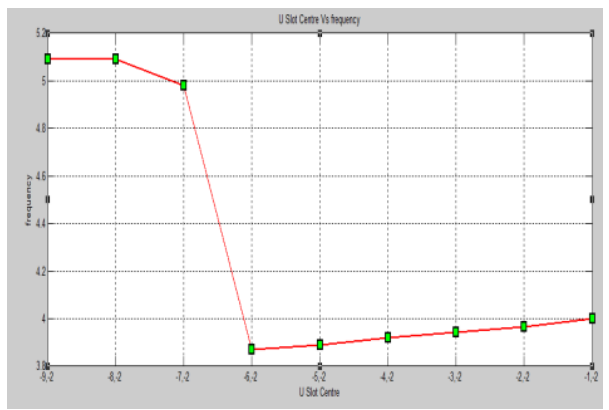

Fig.4.13. Plot of U Slot Centre and Frequency of Negative X Axis

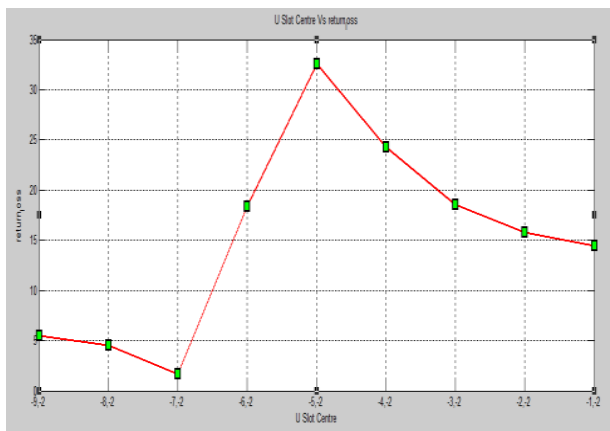

Fig.4.14. Plot of U Slot Centre and Return Loss of Negative X Axis 
Fig. 4.15 and 4.16 represents the effect of $U$ slot position on gain and bandwidth of the antenna. Fig. 4.15 shows the increase in gain with the shifting of $U$ slot centre along negative $\mathrm{x}$ axis. But this increase is upto the position at points of $(6,-2)$. Fig. 4.16 shows the degradation in bandwidth with shifting of $U$ slot centre away from the origin along negative $\mathrm{x}$ axis.

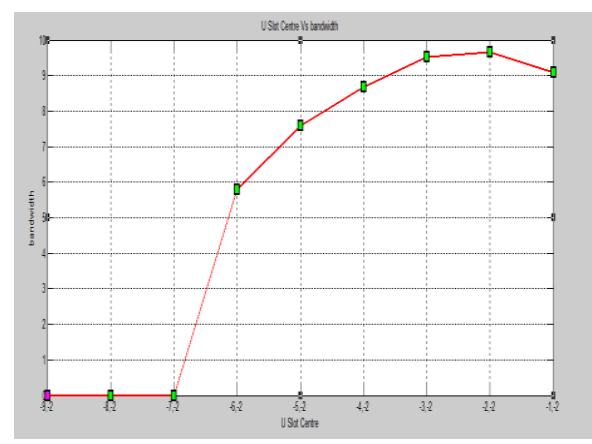

Fig.4.15. Plot of U Slot Centre and Gain of Negative X Axis

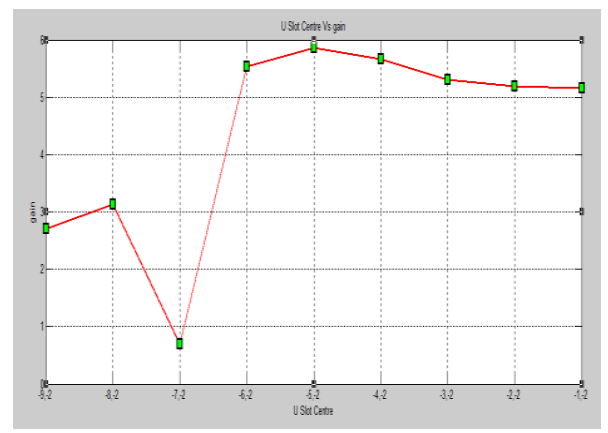

Fig.4.16. Plot of U Slot Centre and Bandwidth of Negative X Axis.

\section{Conclusions}

After this variation of $U$ slot along all its axis it is concluded that The variation of position of the slot towards increasing positive y axis gives all the parameters degrading in their performance.

- With the variation of $\mathrm{U}$ slot along negative y axis, all the parameters are giving better results in their performance at the cost of bandwidth.

- The variation of $\mathrm{U}$ slot among positive $\mathrm{X}$ axis gives better performance of all its parameters. But this performance is up to some point $(6,-2)$.

- With the variation of $U$ slot among negative $X$ axis, $U$ slot gives better performance of all its parameters. But this performance is up to some point $(-6,-2)$.

Therefore the results show that the variation of $U$ slot position effects the antenna's performance viz parameters like resonant frequency, gain, bandwidth.

In case of variation of $U$ slot position along with all the axis, the best position has been analyzed where all the antenna parameters have improved performance. It is seen from the simulations that the optimal point of the variation of position of $U$ slot centre is $(0,-5)$ w.r.t. all the axis where the resonant frequency and return loss is reduced to 3.57 and -33.93 respectively. The gain increases upto $6 \mathrm{~dB}$. 


\section{References}

[1] Balanis, C.A, Antenna Theory Analysis and Design, Wiley Publishers, (2005).

[2] Ansari, J.A. and Mishra, A. Analysis of L-Shaped Slot Loaded Circular Disk Patch Antenna for Satellite and Radio Telecommunication, Wireless Personnel Communication, (2012), vol. 70, pp. 927-943.

[3] Kumar, G. and Ray, K.P. Broadband Microstrip Antennas, Artech House, Waterhouse, R.B.J (2003).

[4] J. A. Ansari, R. B. Ram, and P. Singh. Analysis of a gap-coupled stacked annular ring microstrip antenna, Progress in Electromagnetics Research B, (2008) Vol. 4, 147-158.

[5] S. S. Yavalkar, R. T. Dahatonde. And S. S. Rathod. Parametric Study of Rectangular Microstrip Patch Antenna, IOSR Journal of Electronics and Communication Engineering (IOSR-JECE), (Mar. - Apr. 2013), Volume 5, Issue 2 pp 49-53.

[6] Surmeli, K. and Turetken, B .U-Slot Stacked Patch Antenna Using High and Low Dielectric Constant. Material Combinations in S-band, (2011).

[7] Uzer, M.S., Uzer, D., Yilmaz, N. and Gultekin, S.S. Bandwidth Modelling of U Slot Rectangular Microstrip Antenna with Artificial Neural Networks" Proceedings of Progress in Electromagnetic Research Symposium, Kuala Lumpur, MALAYSIA, (2012), pp. 559-563.

[8] Uzer, D., Uzer, M.S., Gultekin, S.S. and Yilmaz, N. Effect of U Slot Applications on Circular Microstrip Patches Modelling with Artifical Neural Network on Impedance Bandwidth, Proceedings of Progress in Electromagnetic Research Symposium, Kuala Lumpur, MALAYSIA, (2012), pp. 554-558.

[9] Weigand, S. and Huff, G.H. Analysis and Design of Broad-Band Single- Layer Rectangular U-Slot Microstrip Patch Antennas, IEEE Transactions on Antenna and Propagation, (2003), vol .51, No. 3, pp. 457-468.

[10] Tong, K.F. and Wong, T.P. Circularly Polarized U-Slot Antenna IEEE Transactions on Antenna and Propagation, (2007), vol. 55, No. 8, pp.2382-2385.

[11] Lee, K. F., K. M. Luk, L. Tongy, Y. L. Yung, and T. Huynh. Experimental study of the rectangular patch with a U-shaped slot IEEE International Symposium Dig., 10-13, 1996.

[12] J.A Ansari, P. Singh, and N.P. Yadav. Analysis of shorting pin loaded half disk patch antenna for wideband operation, Progress in Electromagnetic Research C, 2009 Vol.6, 179- 192.

[13] A. Rani, and R.K. Dawre. Design and Analysis of Rectangular and U slotted Microstrip Antenna for satellite Communication”, International Journal of Computer Applications, 2010, Vol-12, No.7.

[14] Keith R. Carver and James W. Mink. Microstrip Antenna Technology IEEE Transactions on Antennas and Propagation, 1981, Vol. AP-29, No. 1.

[15] R. Arora, A. Kumar, S. Khan, S. Arya. Design Analysis and Comparison of HE and E Shaped Microstrip Patch Antennas International Journal on Communications Antenna and Propagation, 2014, Vol. 4, No. 1, pp. 27-31.

[16] D. M. Pozar, Microwave Engineering: Wiley Inter-science, 2006.

\section{Authors' Profiles}

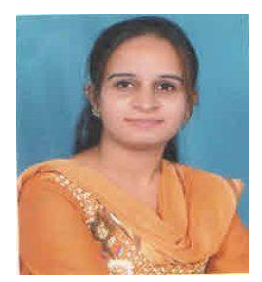

Harleen Kaur received the M. Tech. degree in Electronics and Communication Engining from Guru Nanak Dev Engineering College, Ludhiana, India and Btech in ECE from RIMT, Mandi Gobindgarh. She is working as Assistant Professor in Department of Electronics and Communication Engineering at Sant Baba Bhag Singh Institute of Engg. \& Technology, Jalandhar, India. Her main research interests are development of Neural network and Antenna design. 


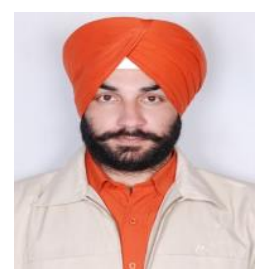

Balwinder Singh Dhaliwal received the B.E. and M. Tech. degrees in Electronics and Communication Engineering from Guru Nanak Dev Engineering College, Ludhiana, India, in 2000 and 2006 respectively. He is working as Assistant Professor in Department of Electronics and Communication Engineering at Guru Nanak Dev Engineering College, Ludhiana, India and pursuing Ph.D. degree at Punjab Technical University, Jalandhar, India. His main research interests are development of neural network and bio-inspired computing based algorithms for fractal antenna design. He is member of IEEE, ISTE, and has been listed in the Who's Who in the world.

How to cite this paper: Harleen Kaur, Balwinder Singh Dhaliwal,"Numerical Analysis of Slot Position of Rectangular U Slot Microstrip Patch Antenna",International Journal of Wireless and Microwave Technologies(IJWMT), Vol.6, No.3, pp.29-39, 2016.DOI: 10.5815/ijwmt.2016.03.04 